Ann. Geophys. Discuss., https://doi.org/10.5194/angeo-2019-23

Manuscript under review for journal Ann. Geophys.

Discussion started: 14 March 2019

(c) Author(s) 2019. CC BY 4.0 License.

\title{
Variation in altitude of high-frequency enhanced plasma line by the pump near the 5th electron gyro-harmonic \\ Jun $\mathrm{Wu}^{\mathrm{a}^{*}}$, Jian $\mathrm{Wu}^{\mathrm{a}}$, Michael. T. Rietveld ${ }^{\mathrm{b}}$, Ingemar. Haggstrom ${ }^{\mathrm{c}}$, Haisheng Zhao ${ }^{\mathrm{a}}$, Tong $\mathrm{Xu}^{\mathrm{a}}$, Zhengwen $\mathrm{Xu}^{\mathrm{a}}$

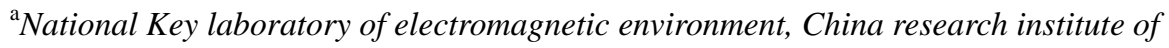 radio wave propagation, Beijing, 102206, China \\ ${ }^{\mathrm{b}}$ EISCAT Scientific Association, 9027 Ramfjordbotn, Norway ${ }^{\mathrm{C}}$ EISCAT Scientific Association, SE-981 92 Kiruna, Sweden
}

\section{Abstract}

During an ionospheric heating campaign carried out at the European Incoherent Scatter Scientific Association (EISCAT), the ultra high frequency incoherent scatter (IS) radar observed a systematic variation in the altitude of the high-frequency enhanced plasma line (HFPL), which behaves depending on the pump frequency. Specifically, the HFPL altitude becomes lower when the pump lies above the 5th gyro-harmonic. The analysis shows that the enhanced electron temperature plays a decisive role in the descent in the HFPL altitude. That is, on the traveling path of the enhanced Langmuir wave, the enhanced electron temperature can only be matched by the low electron density at a lower altitude so that the Bragg condition can be satisfied, as expected from the dispersion relation of Langmuir wave.

Keywords: ionospheric heating, incoherent scatter radar, enhanced plasma line, altitude, Bragg condition. 
Ann. Geophys. Discuss., https://doi.org/10.5194/angeo-2019-23

Manuscript under review for journal Ann. Geophys.

Discussion started: 14 March 2019

(c) Author(s) 2019. CC BY 4.0 License.

\section{Introduction}

The oscillation two stream instability (OTSI) and the parametric decay instability (PDI) have been extensively investigated [Silin 1965; DuBois and Goldman 1965, 1967; Perkins and Flick 1971; Rosenbluth 1972; Drake et al.,, 1974; Perkins, et al.,, 1974; Kuo and Cheo 1978; Wu et al.,, 2006; Wu et al.,, 2007). As the signatures of the PDI and OTSI, the high-frequency enhanced plasma line (HFPL) and the high-frequency enhanced ion line (HFIL) are observed by the incoherent scattering (IS) radar during the ionospheric heating campaign. Using those observations of IS radar, the IS spectrum (Kuo and Fejer, 1972; Stubbe et al., 1992; Kohl et al., 1993; Carlson et al., 1972; Gordon and Carlson,1974; Kantor, 1974; Hagfors et al., 1983; Dubois et al., 1988; Nordling et al., 1988 ; Stubbe et al., 1985), the pump threshold for the PDI and OTSI (Fejer, 1979; Bezzerides and Weinstock, 1972; Weinstock and Bezzerides, 1972), the temporal properties of the PDI and OTSI (Kohl et al., 1993; Gordon and Carlson, 1974; Kantor, 1974; Stubbe et al., 1985; Carlson et al., 1972; Jones et al., 1986) and the altitude properties of the HFPL and HFIL (Stubbe et al., 1992 ; Kohl et al., 1987, 1993; Djuth et al., 1994; Ashrafi et al., 2006; Wu et al., 2017a, 2018b) were examined.

The enhanced Langmuir wave and ion acoustic wave are usually excited in the altitude range from the reflection altitude of the pump to the altitude where the heavy Landau effect on Langmuir wave may take place (Stubbe et al., 1992). However, the enhanced Langmuir wave and ion acoustic wave can't be observed by IS radar in the exciting altitude range, but at an altitude where the Bragg condition is satisfied 
Ann. Geophys. Discuss., https://doi.org/10.5194/angeo-2019-23

Manuscript under review for journal Ann. Geophys.

Discussion started: 14 March 2019

(c) Author(s) 2019. CC BY 4.0 License.

45 (Stubbe et al., 1992; Kohl et al., 1987, 1993). Some usual observations of the ultra

high frequency (UHF) radar at European Incoherent Scatter Scientific Association (EISCAT) show that the HFIL altitude is about $\sim 3 \mathrm{~km}-\sim 5 \mathrm{~km}$ higher than the HFPL altitude (Stubbe et al., 1992; Kohl et al., 1993). Additionally, the altitude extending of $\sim 3 \mathrm{~km}-\sim 5 \mathrm{~km}$ frequently appears in the power profile of the HPIL, but does not in the power profile of the HFPL (Stubbe et al., 1992; Kohl et al., 1993). Moreover, some observations at EISCAT illustrated that a descent in the altitude of the plasma turbulence took place over tens of seconds after the pump on, which was most likely attributed to the modification in electron density by the ionospheric heating (Djuth et al., 1994). UHF radar at EISCAT observed the descent in the HFIL altitude from $230 \mathrm{~km}$ to $\sim 220 \mathrm{~km}$ within $\sim 60 \mathrm{~s}$, which was also attributed to the modification in electron density (Ashrafi et al., 2006).

Although those variations in the HFPL and HFIL altitudes were attributed to the enhanced electron temperature and the modified electron density, the dominant one of which was not clearly identified (Wu et al., 2017a). Furthermore, it was identified that the enhanced electron temperature dominated over the modified electron density in the variation in the HFIL altitude (Wu et al., 2018b). As a further work, this paper examines the variation in the HFPL altitude in more detail. Indeed, the dispersion behavior of Langmuir wave is very different from that of ion acoustic wave.

\section{Experiment and data}

An ionospheric heating campaign was performed at EISCAT at 12:32:30 UT 14:30 UT (universal time) on Mar. 11, 2014. The experiment arrangement has been 
Ann. Geophys. Discuss., https://doi.org/10.5194/angeo-2019-23

Manuscript under review for journal Ann. Geophys.

Discussion started: 14 March 2019

(c) Author(s) 2019. CC BY 4.0 License.

67 described in more detail by Wu et al., (2016, 2017b). Briefly, the EISCAT heater

68 (Rietveld et al., 1993, 2016) radiated the O mode pump in the frequency band of 6.7 $\mathrm{MHz}-7 \mathrm{MHz}$, and the UHF IS radar was operated as the leading diagnostic means. The pump frequency $f_{\mathrm{HF}}$ was stepped down and up in a step of $2.804 \mathrm{kHz}$ with a period of $10 \mathrm{~s}$ as shown in those bottom panels in Figure 1, Figure 2 and Figure 3. During the experiment, the local geomagnetic was relatively quiet. At an altitude of $200 \mathrm{~km}$, the total geomagnetic varied in the range of $49202 \mathrm{nT}-49233 \mathrm{nT}$. Considering the variation in the intensity of ion line, we adopt a convention for the following discussion: the $f_{\mathrm{HF}}$ band of $6.7 \mathrm{MHz}-7 \mathrm{MHz}$ can be divided into three daughter bands, that is, the higher band (HB, above $5 f_{\text {ce }}$ ), the gyro-harmonic band (GB, very close to $5 f_{\text {ce }}$ ) and lower band ( $\mathrm{LB}$, below $5 f_{\text {ce }}$ ), where $f_{\text {ce }}$ represents the electron gyro-frequency (Wu et al., 2016, 2017a, 2017b, 2018a, 2018b, 2019). For instance, in the 1 st heating cycle, the $\mathrm{HB}$ is set as $7 \mathrm{MHz}-\sim 6.871028$ $\mathrm{MHz}$, the GB as $\sim 6.868224 \mathrm{MHz}-\sim 6.837383 \mathrm{MHz}$ and the $\mathrm{LB}$ as $~ 6.834579$ $\mathrm{MHz}$ - 6.7 MHz, which temporally correspond to the time intervals of 12:30:00 UT - 12:37:40 UT, 12:37:50 UT - 12:39:40 UT and 12:39:50 UT - 12:48:00 UT, respectively. Actually, the frequency division in each heating cycle should be somewhat different from each other due to the slight disturbance of the geomagnetic. From the 1st panel to the 6th panel in Figure 1, the normalized plasma lines at those altitudes of $210.25 \mathrm{~km}, 207.32 \mathrm{~km}, 204.39 \mathrm{~km}, 201.45 \mathrm{~km}, 198.52 \mathrm{~km}$ and $195.58 \mathrm{~km}$ are successively given, which lie in the frequency range of $-6.7 \mathrm{MHz}-$ $-7.25 \mathrm{MHz}$. One can find that those HFPLs in the GB and HB lie at frequency 

$f_{\mathrm{HF}}-9.45 \mathrm{kHz}$ as the expected decay line from the PDI. In the GB, those strong HFPLs of up to 1 occur at an altitude of $201.45 \mathrm{~km}$ in the 1 st heating cycle, at an altitude of $210.25 \mathrm{~km}$ in the 2nd heating cycle and at an altitude of $207.32 \mathrm{~km}$ in the 3rd and 4th heating cycles respectively. In the HB, however, those strong HFPLs of up to $\sim 1$ descend in altitude, that is, they are located at an altitude of $198.52 \mathrm{~km}$ in the 1st heating cycle, at altitudes of $207.32 \mathrm{~km}$ and $204.39 \mathrm{~km}$ in the 2nd heating cycle, at an altitude of $204.39 \mathrm{~km}$ in the 3rd and 4th heating cycles. On the other hand, in the LB, the HFPL has not appeared at any of those altitudes due to the absence of the PDI and OTSI (Wu et al., 2019).

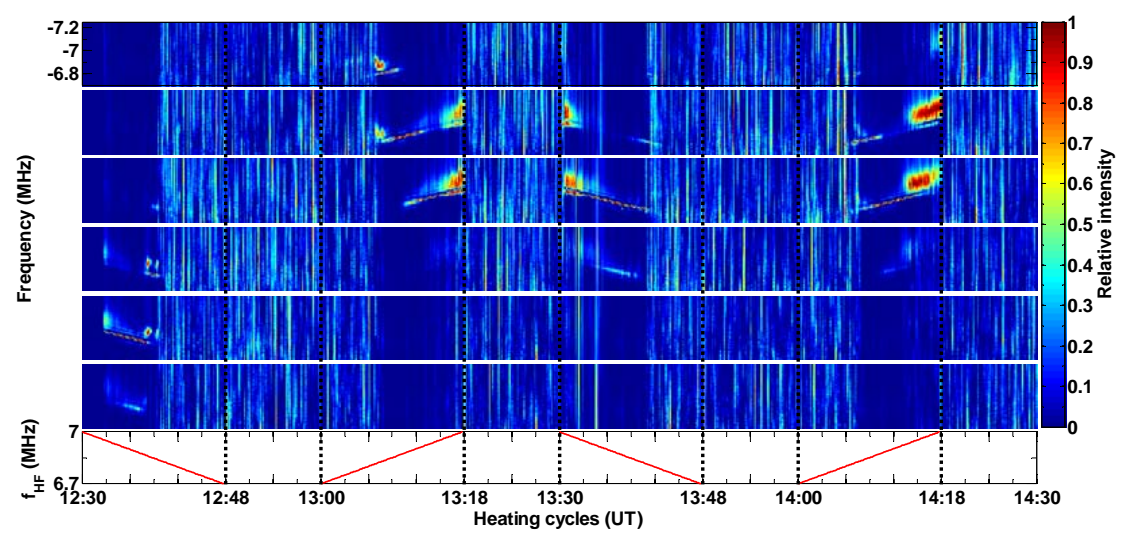

Figure 1. The plasma lines versus $f_{\mathrm{HF}}$ (the heating cycles), where the 1st panel is for an altitude of $210.25 \mathrm{~km}$, the 2nd panel for $207.32 \mathrm{~km}$, the 3rd panel for $204.39 \mathrm{~km}$, the 4th panel for $201.45 \mathrm{~km}$, the 5th panel for $198.52 \mathrm{~km}$, the 6th panel for $195.58 \mathrm{~km}$ and the 7th panel for $f_{\mathrm{HF}}$ (the heating cycles), successively from top to bottom.

Figure 2 gives the altitude profile of $T_{\mathrm{e}} / T_{\mathrm{e} 0}$ as a function of $f_{\mathrm{HF}}$, where $T_{\mathrm{e}}$ is the electron temperature and $T_{\mathrm{e} 0}$ the undisturbed electron temperature. At an altitude of $\sim 200 \mathrm{~km}, T_{\mathrm{e}} / T_{\mathrm{e} 0}$ immediately enhances when heating on, and obviously varies with $f_{\mathrm{HF}} \cdot T_{\mathrm{e}} / T_{\mathrm{e} 0}$ strongly enhances up to $\sim 1.5$ in the LB, whereas it slightly 
Ann. Geophys. Discuss., https://doi.org/10.5194/angeo-2019-23

Evidently, $\left(T_{\mathrm{e}} / T_{\mathrm{e} 0}\right)_{\mathrm{LB}}>\left(T_{\mathrm{e}} / T_{\mathrm{e} 0}\right)_{\mathrm{HB}}>\left(T_{\mathrm{e}} / T_{\mathrm{e} 0}\right)_{\mathrm{GB}}$, where $\left(T_{\mathrm{e}} / T_{\mathrm{e} 0}\right)_{\mathrm{LB}}, \quad\left(T_{\mathrm{e}} / T_{\mathrm{e} 0}\right)_{\mathrm{HB}}$ and $\left(T_{\mathrm{e}} / T_{\mathrm{e} 0}\right)_{\mathrm{GB}}$ represent $T_{\mathrm{e}} / T_{\mathrm{e} 0}$ in the LB, HB and GB respectively. This variation in

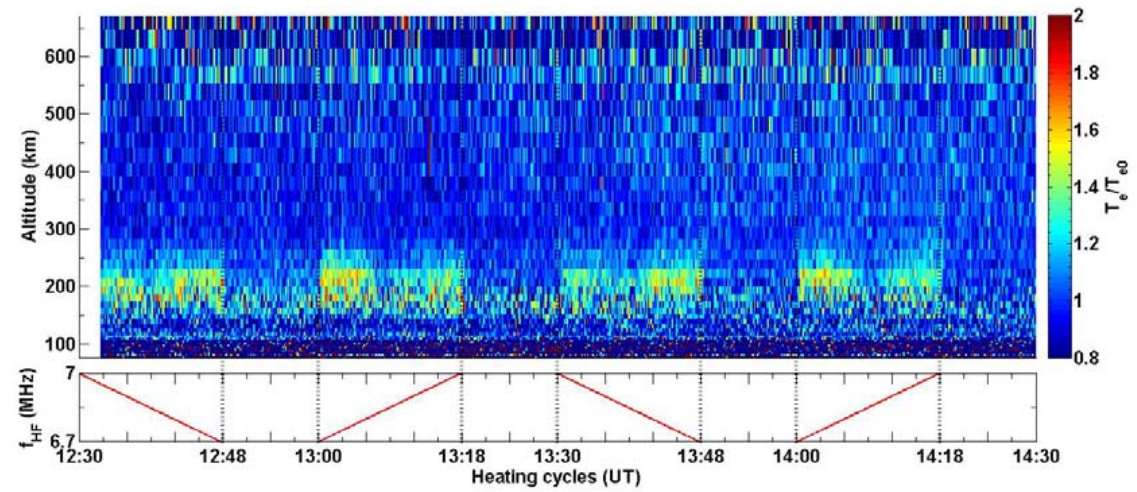

Figure 3 is the altitude profile of $N_{\mathrm{e}} / N_{\mathrm{e} 0}$ as a function of $f_{\mathrm{HF}}$, where $N_{\mathrm{e}}$ is the electron density and $N_{\mathrm{e} 0}$ the undisturbed electron density. In the 3rd and 4th heating cycles, the enhanced $N_{\mathrm{e}} / N_{\mathrm{e} 0}$ of up to $\sim 1.4$ take place in the GB and HB and can be seen in a narrow region around an altitude of $\sim 200 \mathrm{~km}$. In accordance with the standard IS analysis, the enhanced $N_{\mathrm{e}} / N_{\mathrm{e} 0}$ should not correspond to the real enhancement in the electron density, but to the HFIL excited by the PDI and OTSI (Wu et al., 2017b). On the other hand, no apparent enhancement in $N_{\mathrm{e}} / N_{\mathrm{e} 0}$ takes place around an altitude of $\sim 200 \mathrm{~km}$ in the 1st and 2nd heating cycles. This may be due to 
Ann. Geophys. Discuss., https://doi.org/10.5194/angeo-2019-23

the high background electron density and the ambiguity of radar measurement (Wu et al., 2017b). Additionally, the enhanced $N_{\mathrm{e}} / N_{\mathrm{e} 0}$ appears over a wide altitude range of $\sim 250 \mathrm{~km} \sim \sim 670 \mathrm{~km}$, which is hardly explained by the standard IS analysis and is open (Wu et al., 2017b).

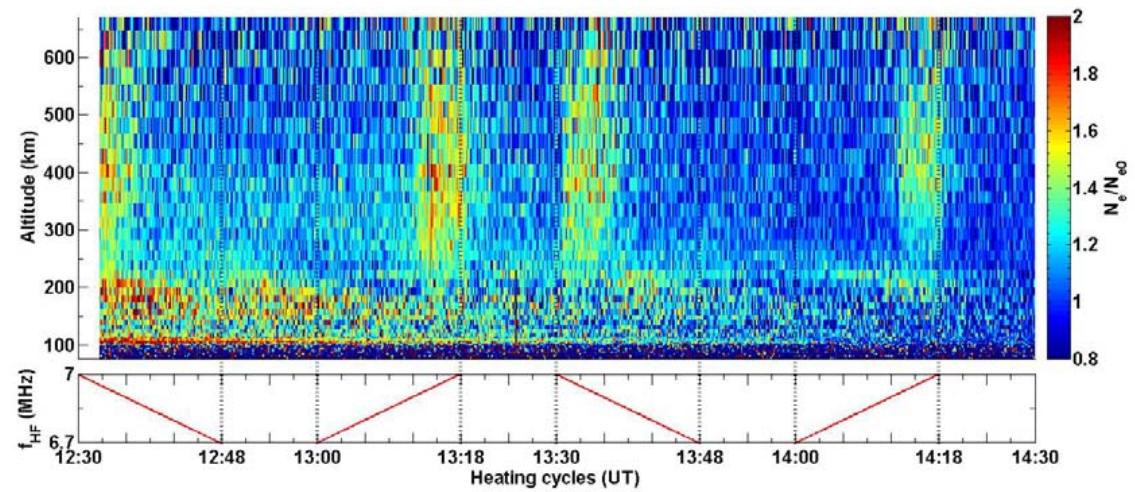

Figure 3. $N_{\mathrm{e}} / N_{\mathrm{e} 0}$ versus $f_{\mathrm{HF}}$ (the heating cycles), where $N_{\mathrm{e} 0}$ is obtained by averaging the electron density over the final 5 minutes of the UHF radar observations at 14:25 UT - 14:30 UT.

In summary, Figure 1 shows that (1) the HFPL altitude in the 1st heating cycle is far lower than that in the 2nd, 3rd and 4th heating cycles; (2) interestingly enough, those HFPL altitudes in the GB and HB systematically vary with $f_{\mathrm{HF}}$, that is, the HFPL altitude in the HB is slightly lower than that in the GB. Additionally, Figure 2 implies that $T_{e}$ also systematically varies with $f_{\mathrm{HF}}$, whereas $N_{\mathrm{e}}$ does not as illustrated in Figure 3.

\section{Discussion}

OTSI and PDI can be excited in the altitude range of (Stubbe et al., 1992)

$$
h_{0}-0.1 H \leq h_{\mathrm{ex}}<h_{0}
$$

where $h_{0}$ is the reflection altitude of the pump, $H$ is the scale altitude and $h_{\mathrm{ex}}$ is 
Ann. Geophys. Discuss., https://doi.org/10.5194/angeo-2019-23

Manuscript under review for journal Ann. Geophys.

Discussion started: 14 March 2019

(c) Author(s) 2019. CC BY 4.0 License. monotonous change in the profile of $N_{\mathrm{e}}$ below the ionospheric peak, $h_{\mathrm{ex}}$ in the HB should be higher than that in the GB. In Figure 3, it is evident that $N_{\mathrm{e}} / N_{\mathrm{e} 0}$ in the $1 \mathrm{st}$ heating cycle reaches $~ 1.7$ near an altitude of $200 \mathrm{~km}$ and is far larger than that in the 2nd, 3rd and 4th heating cycles. This implies that $h_{0}$ in the 1st heating cycle should be far lower than that in the 2nd, 3rd and 4th heating cycles. Correspondingly, $h_{\mathrm{ex}}$ and the HFPL altitude in the 1st heating cycle should be far lower than that in the 2nd, 3rd and 4th heating cycles.

However, function (1) fails to explain that the HFPL altitude in the HB is slightly lower than that in the GB. Considering an field-aligned and monostatic operating observation, the enhanced Langmuir wave traveling in a non-uniform and stationary ionosphere should satisfy the dispersion relation (Kohl et al., 1993)

$$
\omega_{\mathrm{L}}^{2}=\omega_{\mathrm{pe}}^{2}+\gamma \frac{K_{\mathrm{B}} T_{\mathrm{e}}}{m_{\mathrm{e}}} k_{\mathrm{L}}^{2}
$$

where $\omega_{\mathrm{L}}$ is the angular frequency of Langmuir wave, $\omega_{\mathrm{pe}}$ is the Langmuir angular frequency of ionospheric plasma, $\gamma$ is the adiabatic index, $K_{\mathrm{B}}$ is the Boltzmann constant, $k_{\mathrm{L}}$ is the wave number of Langmuir wave, and $m_{\mathrm{e}}$ is the electron mass.

When the enhanced Langmuir wave travels in a non-uniform and stationary ionosphere, $k_{\mathrm{L}}$ may change, whereas $\omega_{\mathrm{L}}$ will not change. That is, $k_{\mathrm{L}}$ should depend on $\omega_{\mathrm{pe}}$ and $T_{\mathrm{e}}$ on the traveling path of the enhanced Langmuir wave, as expected from function (2). This implies that at a particular altitude, $k_{\mathrm{L}}$ will satisfies the Bragg condition, namely, $k_{\mathrm{L}}=2 k_{\mathrm{r}}$, and the enhanced Langmuir wave should be observed by radar, where $k_{\mathrm{r}}$ is the wave number of radar. Then, considering $T_{\mathrm{e}}=T_{\mathrm{e}}^{\prime}$, 
Ann. Geophys. Discuss., https://doi.org/10.5194/angeo-2019-23

Manuscript under review for journal Ann. Geophys.

Discussion started: 14 March 2019

(c) Author(s) 2019. CC BY 4.0 License.

the enhanced Langmuir wave should be observed at an altitude of $h^{\prime}$ where

$1662 k_{\mathrm{r}}=k_{\mathrm{L}}=\sqrt{\frac{\left(\omega_{\mathrm{L}}^{2}-\omega_{\mathrm{pe}}^{\prime 2}\right) m_{\mathrm{e}}}{\gamma \mathrm{K}_{\mathrm{B}} T_{\mathrm{e}}^{\prime}}}$, which is a derivation of function (2). On the other hand,

$T_{\mathrm{e}}=T_{\mathrm{e}}^{\prime \prime} \quad$ is considered, then the enhanced Langmuir wave should be observed at other

altitude of $h^{\prime \prime}$, where $2 k_{\mathrm{r}}=k_{\mathrm{L}}=\sqrt{\frac{\left(\omega_{\mathrm{L}}^{2}-\omega_{\mathrm{pe}}^{\prime \prime 2}\right) m_{\mathrm{e}}}{\gamma \mathrm{K}_{\mathrm{B}} T_{\mathrm{e}}^{\prime \prime}}}$. Obviously, $\frac{\omega_{\mathrm{L}}^{2}-\omega_{\mathrm{p}}^{\prime \prime 2}}{T_{\mathrm{e}}^{\prime \prime}}=\frac{\omega_{\mathrm{L}}^{2}-\omega_{\mathrm{pe}}^{\prime 2}}{T_{\mathrm{e}}^{\prime}}$

169

170

171

172

can be obtained. Furthermore, if $T_{\mathrm{e}}{ }^{\prime \prime}>T_{\mathrm{e}}{ }^{\prime}$, then $\omega_{\mathrm{pe}}{ }^{\prime \prime}<\omega_{\mathrm{pe}}{ }^{\prime}$. Due to the monotonous profile of $\omega_{\mathrm{pe}}$ below the ionospheric peak, $h^{\prime \prime}<h^{\prime}$ will be obtained. In other word, on the traveling path of the enhanced Langmuir wave, the higher $T_{\mathrm{e}}$ is, the lower the observing altitude of the enhanced Langmuir wave is. The fact is $\left(T_{\mathrm{e}} / T_{\mathrm{e} 0}\right)_{\mathrm{HB}}>\left(T_{\mathrm{e}} / T_{\mathrm{e} 0}\right)_{\mathrm{GB}}$ as shown in Figure 2. As a result, the HFPL altitude in the HB should be lower than that in the GB as shown in Figure 1.

As an example, the HFPL in the 4th heating cycle is examined. The left panel of Figure 4 respectively gives the profiles of $\omega_{\mathrm{L}}^{2}-\omega_{\mathrm{pe}}^{2}, T_{\mathrm{eGB}}$ and $T_{\mathrm{eHB}}$ in the altitude range of $190 \mathrm{~km}-230 \mathrm{~km}$ in the 4th heating cycle. Here, the profile of $\omega_{\mathrm{L}}^{2}-\omega_{\mathrm{pe}}^{2}$ is not distinguished in the GB and HB, implying an assumption that the profiles of $N_{\mathrm{e}}$ was not modified by the ionospheric heating. Indeed, it is difficult to measure the slight modification in electron density due to (1) $N_{\mathrm{e}}$ is much variable in space and time, and (2) the artificial modification in $N_{\mathrm{e}}$ is relatively small (Rietveld et al., 2003). Also, Figure 3 really exhibits that no real modification in $N_{\mathrm{e}} / N_{\mathrm{e} 0}$ is induced by the ionospheric heating in the altitude range examined (Wu et al., 2017b). Obviously, $\omega_{\mathrm{L}}^{2}-\omega_{\mathrm{pe}}^{2}$ monotonically decreases with the ascent in altitude and has a vertical gradient of $\sim-3.1 \times 10^{15} \operatorname{rad}^{2} \mathrm{~s}^{2} \mathrm{~km}^{-1}$ in the altitude range of $200 \mathrm{~km}-230$ 
Ann. Geophys. Discuss., https://doi.org/10.5194/angeo-2019-23

Manuscript under review for journal Ann. Geophys.

Discussion started: 14 March 2019

(c) Author(s) 2019. CC BY 4.0 License.

km. Moreover, $\omega_{\mathrm{L}}^{2}-\omega_{\mathrm{pe}}^{2}$ becomes negative above an altitude of $\sim 208.5 \mathrm{~km}$ due to the increasing $N_{\mathrm{e}}$ with the ascent in altitude. In addition, the profile of $T_{\mathrm{eGB}}$ demonstrates the gradient of $\sim 6.09 \mathrm{Kkm}^{-1}$ within the altitude range of $190 \mathrm{~km}$ $200 \mathrm{~km}$ and $\sim-8.85 \mathrm{Kkm}^{-1}$ within the altitude range of $200 \mathrm{~km}-230 \mathrm{~km}$, whereas $T_{\text {eHB }}$ demonstrates the gradient of $\sim 40.82 \mathrm{Kkm}^{-1}$ within the altitude range of $190 \mathrm{~km}-200 \mathrm{~km}$ and $\sim-17.77 \mathrm{Kkm}^{-1}$ within the altitude range of $200 \mathrm{~km}$ $230 \mathrm{~km}$. This implies that the strongest enhancement in $T_{\mathrm{e}}$ takes place an altitude of $\sim 200 \mathrm{~km}$ and the thermal energy should be conducted along the magnetic field within an extending altitude range.
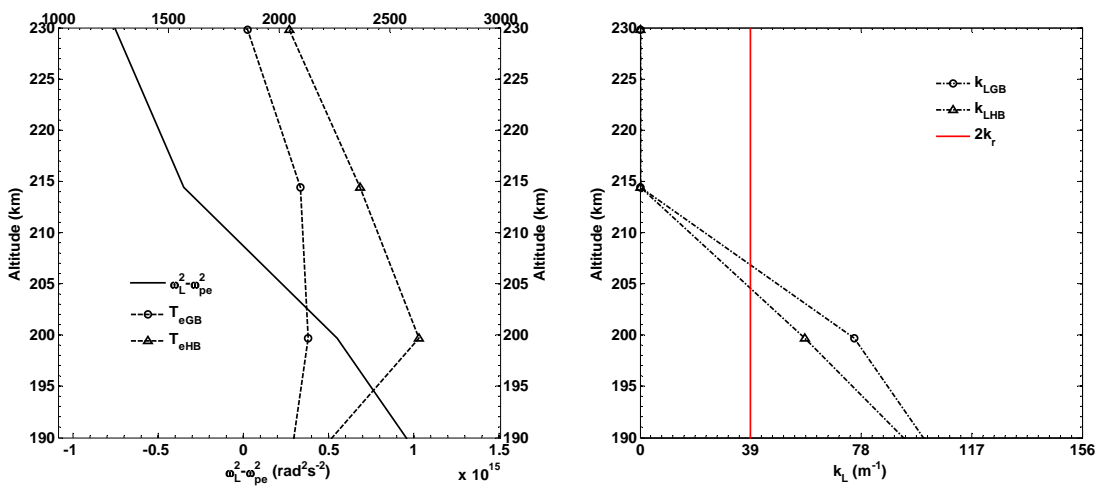

Figure 4. The altitude profiles of $\omega_{\mathrm{L}}^{2}-\omega_{\mathrm{pe}}^{2}, T_{\mathrm{eGB}}, T_{\mathrm{eHB}}$ (the left panel), $k_{\mathrm{LGB}}, k_{\mathrm{LHB}}$ and $k_{\mathrm{r}}$ (the right panel), where $\omega_{\mathrm{L}}=2 \pi \times 6.8 \mathrm{MHz}, \omega_{\mathrm{pe}}=2 \pi \times 8.9 \sqrt{N_{e}}, N_{\mathrm{e}}$ is obtained by averaging over the time interval of [14:07:20 UT, 14:09:10 UT], $T_{\mathrm{eGB}}$ and $T_{\mathrm{eHB}}$ are obtained by averaging over the time intervals of [14:07:20 UT, 14:09:10 UT] and [14:11:20 UT, 14:18:00 UT], respectively, and $k_{\mathrm{r}}=19.5 \mathrm{~m}^{-1}$ is the wave number of EISCAT UHF radar. 
Ann. Geophys. Discuss., https://doi.org/10.5194/angeo-2019-23

Manuscript under review for journal Ann. Geophys.

Discussion started: 14 March 2019

(c) Author(s) 2019. CC BY 4.0 License.

range of $190 \mathrm{~km}-230 \mathrm{~km}$ in the 4th heating cycle are demonstrated, where $k_{\mathrm{LGB}}$ and $k_{\mathrm{LHB}}$ represent the wave numbers of the enhanced Langmuir wave in the GB and HB. The profile of $k_{\mathrm{LGB}}$ has a gradient of $\sim-2.78 \mathrm{~m}^{-1} \mathrm{~km}^{-1}$ within the altitude range of $190 \mathrm{~km}-200 \mathrm{~km}$ and $\sim-5.1 \mathrm{~m}^{-1} \mathrm{~km}^{-1}$ within the altitude range of $200 \mathrm{~km}-214.4$ $\mathrm{km}$, and $k_{\mathrm{LGB}}=2 k_{\mathrm{r}}$ takes place at an altitude of $\sim 206.8 \mathrm{~km}$. Moreover, the profile of $k_{\mathrm{LHB}}$ demonstrates a gradient of $\sim-3.15 \mathrm{~m}^{-1} \mathrm{~km}^{-1}$ within an altitude range examined, and $k_{\mathrm{LHB}}=2 k_{\mathrm{r}}$ at an altitude of $\sim 204.5 \mathrm{~km}$. This indicates that the enhanced $T_{\mathrm{e}}$ on the traveling path can remarkably impact on $k_{\mathrm{L}}$, and the enhanced Langmuir waves in the GB and HB should be observed at different altitude, namely, $206.8 \mathrm{~km}$ in the GB and $204.5 \mathrm{~km}$ in the HB respectively. Thus, the altitude difference between the HFPL altitudes in the GB and HB is $2.3 \mathrm{~km}$ as illustrated in the right panel of Figure 4. Taking the height resolution of $\sim 3 \mathrm{~km}$ of EISCAT UHF radar into account, the HFPL altitudes in the GB and HB in the 4th heating cycle shown in

Figure 1 are in perfect agreement with the altitudes of $k_{\mathrm{LGB}}=2 k_{\mathrm{r}}$ and $k_{\mathrm{LHB}}=2 k_{\mathrm{r}}$ above an altitude of $~ 208.5$, implying the enhanced Langmuir wave will be reflected at an altitude of $\sim 208.5 \mathrm{~km}$. does not imply that the enhanced $T_{\mathrm{e}}$ is independent of the HFPL altitude. Indeed, on the traveling path of Langmuir wave, an remarkable enhancement in electron temperature owing to an ionospheric heating will take significant impact on $k_{\mathrm{L}}$. For a 
Ann. Geophys. Discuss., https://doi.org/10.5194/angeo-2019-23

Manuscript under review for journal Ann. Geophys.

Discussion started: 14 March 2019

(c) Author(s) 2019. CC BY 4.0 License. remarkable descent in the HFPL altitude. Moreover, if a small gradient profile of $N_{\text {e }}$

227 is considered, that is, $N_{\mathrm{e}}$ can be approximately considered as a constant, then $k_{\mathrm{L}}$ 228 will be mainly determined by the profile of $T_{\mathrm{e}}$.

\section{Conclusions}

A systematic variation in the HFPL altitude induced by the pump near the 5 th gyro-harmonic at EISCAT, is paid attention. The IS radar observation demonstrates that the HFPL altitude and the electron temperature behave as a function of the pump frequency. More specifically, when the pump frequency approaches the 5th gyro-harmonic from below, the electron temperature is somewhat enhanced, and the HFPL is observed at an altitude as expected. When the pump frequency sweeps above the 5th gyro-harmonic, however, the electron temperature is prominently enhanced, and the HFPL altitude slightly plunge downward.

In conclusion, the HFPL altitude is dependent on the dispersion behavior of the enhanced Langmuir wave and the Bragg condition, and is determined by the profiles of the electron density and the enhanced electron temperature. When heating above the 5th gyro-harmonic, the HFPL altitude plunge downward owing to the thermal effect of ionospheric heating on the traveling path of the enhanced Langmuir wave. In other word, when the pump sweeps above the 5th gyro-harmonic, the IS radar should observe the enhanced Langmuir wave at an lower altitude, where the low electron density can compensate the remarkably enhanced electron temperature so that the Bragg condition can be satisfied, as expected by the dispersion relation of Langmuir 
Ann. Geophys. Discuss., https://doi.org/10.5194/angeo-2019-23

Manuscript under review for journal Ann. Geophys.

Discussion started: 14 March 2019

(c) Author(s) 2019. CC BY 4.0 License.

\section{Acknowledgments}

We would like to thank the engineers of EISCAT in Tromsø for keeping the

facility in excellent working condition and Tromsø Geophysical Observatory, UiT The

Arctic University of Norway, for providing the magnetic data of Tromsø recorded on

11 Mar. 2014. The data of UHF radar can be obtained freely from EISCAT

Japan and Institute for Space-Earth Environmental Research at Nagoya University), and the UK (the Natural Environment Research Council).

\section{References}

Ashrafi M., Kosch, M. J., and Honary, F.: Heater-induced altitude descent of the EISCAT UHF ion line enhancements: Observations and modeling, Advances in Space Research, 38, 2645-2652, https://doi.org/10.1016/j.asr.2005.06.079 , 2006.

Bezzerides, B. and Weinstock, J.: Nonlinear saturation of parametric instabilities,

Phys. Rev. Lett., 28, 481- 484, https://doi.org/10.1103/PhysRevLett.28.481, 1972. 1242-1250, https://doi.org/10.1029/JA077i007p01242,1972. 
Ann. Geophys. Discuss., https://doi.org/10.5194/angeo-2019-23

Manuscript under review for journal Ann. Geophys.

Discussion started: 14 March 2019

(c) Author(s) 2019. CC BY 4.0 License.

272 instabilities of electromagnetic waves in plasmas, Phys. Fluids, 17, 778-785,

273 https://doi.org/10.1063/1.1694789, 1974.

274 Dubois D. F., Rose, H., and Russell, D.: Power spectra of fluctuations in strong

275 Langmuir turbulence, Phys. Rev. Lett., 61, 2209-2212,

276 https://doi.org/10.1103/PhysRevLett.61.2209, 1988.

277 DuBois, D. F. and Goldman M. V.: Parametrically excited plasma fluctuations, Phys.

278 Rev., 164, 207-222, https://doi.org/10.1103/PhysRev.164.207, 1967.

279 DuBois, D. F. and Goldman, M. V.: Radiation induced in stability of electron plasma

280 oscillations, $\quad$ Phys. $\quad$ Rev. $\quad$ Lett., $14, \quad$ 544-546,

281 https://doi.org/10.1103/PhysRevLett.14.544, 1965.

282 Fejer, J. A.: Ionospheric modification and parametric instabilities, Reviews of

283 Geophysics and $\quad$ space $\quad$ physics, 135-153,

284 https://doi.org/10.1029/RG017i001p00135, 1979.

285 Gordon, W. E. and Carlson, H. C.: Arecibo heating experiments, Radio Sci., 9,

286 1041-1047, https://doi.org/10.1029/RS009i011p01041, 1974.

287 Gurevich, A. V.: Nonlinear effects in the ionosphere, Physics Uspekhi, 50, 1091-1121,

288 https://doi.org/10.1070/PU2007v050n11ABEH006212, 2007.

289 Hagfors, T., Kofman, W., Kopka, H., and Stubbe, P.: Observations of enhanced plasma

290 lines by EISCAT during heating experiments, Radio Sci., 18, 861-866,

291 https://doi.org/10.1029/RS018i006p00861, 1983.

292 Jones, T. B., Robinson, T. R., Stubbe, P., and Kopka, H.: EISCAT observations of the

293 heated ionosphere, J. Atmosph. Terr. Phys., 48, 1027-1035,

294 https://doi.org/10.1016/0021-9169(86)90074-7, 1986.

295 Kantor, I. J.: High frequency induced enhancements of the incoherent scatter spectrum

296 at Arecibo. II, J. Geophys. Res., 79, 199-208,

297 https://doi.org/10.1029/JA079i001p00199, 1974.

298 Kohl, H. W., Kopka, H., Lahoz, C., and Stubbe, P.: Propagation of artificially excited

299 Langmuir waves in the ionosphere, Radio Sci., 22, 655-661,

300 https://doi.org/10.1029/RS022i004p00655, 1987.

301 Kohl, H., Kopka, H., Stubbe, P., and Rietveld, M. T.: Introduction to ionospheric 
Ann. Geophys. Discuss., https://doi.org/10.5194/angeo-2019-23

Manuscript under review for journal Ann. Geophys.

Discussion started: 14 March 2019

(c) Author(s) 2019. CC BY 4.0 License.

heating experiments at Tromsø-II. Scientific problems, J. Atmos. Terr. Phys., 55, 601-603, https://doi.org/10.1016/0021-9169(93)90008-M, 1993.

Kuo, S. P. and Chen, B. R.: Parametric excitation of coupled plasma waves, Phys. Fluids, 21, 1753-1757, https://doi.org/10.1063/1.862091, 1978.

Kuo, Y. Y. and Fejer, J. A.: Spectral-line structures of saturated parametric instabilities, Phys. Rev. Lett., 29, 1667-1670, https://doi.org/10.1103/PhysRevLett.29.1667, 1972. Nordling, J., Hedberg, A., Wannberg, G., Leyser, T. B., Derblom, H., Opgenoorth, H. J., and Lahoz, C.: Simultaneous bistatic European Incoherent Scatter UHF, 145 - MHz radar and stimulated electromagnetic emission observations during $\mathrm{HF}$ ionospheric modification, Radio $\quad$ Sci., 23, 809-819, https://doi.org/10.1029/RS023i005p00809, 1988.

Perkins F. W. and Flick J.: Parametric Instabilities in Inhomogeneous Plasmas, Phys. Fluids, 14, 2012-2018, https://doi.org/10.1063/1.1693711, 1971.

Perkins, F. W., Oberman, C., and Valeo, E. J.: Parametric instabilities and ionospheric $\begin{array}{llll}\text { modification, } & \text { J. } & \text { Geophys. } & \text { Res., }\end{array}$ https://doi.org/10.1029/JA079i010p01478, 1974.

Rietveld, M. T. , Kosch, M. J., Blagoveshchenskaya, N. F., Kornienko, V. A., and Yeoman, T. K.: Ionospheric electron heating, optical emissions, and striations induced by powerful hf radio waves at high latitudes: aspect angle dependence, J. Geophys. Res., 108, 1141-1156, https://doi.org/10.1029/2002JA009543, 2003.

Rietveld, M. T., Kohl, H., Kopka, H., and Stubbe, P.: Introduction to ionospheric heating at Tromsø-I. Experimental overview, J. Atmos. Terr. Phys., 55, 577-599, https://doi.org/10.1016/0021-9169(93)90007-L, 1993.

Rietveld, M. T., Senior, A., Markkanen, J., and Westman, A.: New capabilities of the upgraded EISCAT high-power HF facility, Radio Sci., 51, 1533-1546, https://doi.org/10.1002/2016RS006093, 2016.

Rosenbluth, M. N.: Parametric instabilities in inhomogeneous media, Phys. Rev. Lett., 29, 565-567, https://doi.org/10.1103/PhysRevLett.29.565, 1972.

Silin, V. P.: Parametric resonance in a plasma, Sov. Phys. JETP, Engl. Transl., 21, 1127-1134, 1965. 
Ann. Geophys. Discuss., https://doi.org/10.5194/angeo-2019-23

Manuscript under review for journal Ann. Geophys.

Discussion started: 14 March 2019

(c) Author(s) 2019. CC BY 4.0 License.

Stubbe P., Kohl, H., and Rietveld, M. T.: Langmuir turbulence and ionospheric modification, J. Geophys. Res., 97, 6285-6297, https://doi.org/10.1029/91JA03047, 1992.

Stubbe P., Kopka, H., Rietveld, M. T., Frey, A., Høeg, P., Kohl, H., Nielsen, E., and Rose, G.: Ionospheric modification experiments with the Tromsø heating facility, J. Atmos. Terr. Phys., 47, 1151-1163, https://doi.org/10.1016/0021-9169(85)90085-6, 1985.

Weinstock, J. and Bezzerides, B.: Threshold of ionospheric modifications by radio waves, J. Geophys. Res., 77, 761-764, https://doi.org/10.1029/JA077i004p00761, 1972.

Wu J., Wu, J., and LaHoz, C.: On the ponderomotive force and the effect of loss reaction on parametric instability, Chinese Physics, 16, 558-563, https://doi.org/10.1088/1009-1963/16/2/046, 2007.

Wu J., Wu, J., Rietveld, M. T., Haggstrom, I., Zhao, H., and Xu, Z.: Altitude and intensity characteristics of parametric instability excited by an HF pump wave near the fifth electron harmonic, Plasma Sci. Technol., 19, 125303(7pp), https://doi.org/10.1088/2058-6272/aa9027, 2017a

Wu, J., Wu, J., Rietveld, M. T., Haggstrom, I., Xu, Z., zhang, Y., Xu, T., and Zhao, H.: The intensities of high frequency - enhanced plasma and ion lines during ionospheric heating, J. Geophys. Res., 124, 603-615, https://doi.org/10.1029/2018JA025918, 2019.

Wu, J., Wu, J., Rietveld, M. T., Haggstrom, I., Xu, Z., and Zhao, H.: The extending of observing altitudes of plasma and ion lines during ionospheric heating, J. Geophys. Res., 123, 918-930, https://doi.org/10.1002/2017JA024809, 2018a.

Wu, J., Wu, J., Rietveld, M. T., Haggstrom, I., Zhao, H., Xu, T., and Xu, Z.: Systematic variation in observing altitude of enhanced ion line by the pump near fifth gyroharmonic, Plasma Sci. Technol., 20, 125301(8pp), https://doi.org/10.1088/2058-6272/aadd44, 2018b.

Wu, J., Wu, J., Rietveld, M. T., Haggstrom, I., Zhao, H., and Xu, Z.: The behavior of electron density and temperature during ionospheric heating near the fifth electron 
Ann. Geophys. Discuss., https://doi.org/10.5194/angeo-2019-23

Manuscript under review for journal Ann. Geophys.

Discussion started: 14 March 2019

(c) Author(s) 2019. CC BY 4.0 License.

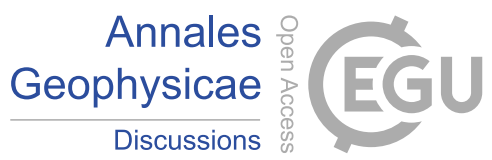

(c) (1)

362 gyrofrequency, J. Geophys. Res., 122, 1277-1295,

363 https://doi.org/10.1002/2016JA023121, 2017b.

$364 \mathrm{Wu}, \mathrm{J} ., \mathrm{Wu}, \mathrm{J}$. , and $\mathrm{Xu}, \mathrm{Z} .:$ Results of ionospheric heating experiments involving an

365 enhancement in electron density in the high latitude ionosphere, Plasma Sci. Technol.,

366 18, 890-896, https://doi.org/10.1088/1009-0630/18/9/03, 2016.

367 Wu, J., Wu, J., and Xue, Y.: The effect of the production and loss reactions on the

368 parametric instability, International Journal of Computational Fluid Dynamics, 20,

369 491-496, https://doi.org/10.1080/10618560600909986, 2006.

370 